\title{
ARTICLE
}

\section{Web Content Strategy in Practice within Academic Libraries}

Courtney McDonald and Heidi Burkhardt

\section{ABSTRACT}

Web content strategy is a relatively new area of practice in industry, in higher education, and, correspondingly, within academic and research libraries. The authors conducted a web-based survey of academic and research library professionals in order to identify present trends in this area of professional practice by academic librarians and to establish an understanding of the degree of institutional engagement in web content strategy within academic and research libraries. This article presents the findings of that survey. Based on analysis of the results, we propose a web content strategy maturity model specific to academic libraries.

\section{INTRODUCTION}

Our previous article traced the history of library adoption of web content management systems (CMS), the evolution of those systems and their use in day-to-day library operations, and the corresponding challenges as libraries have attempted to manage increasingly prolific content creation workflows across multiple, divergent CMS platforms. ${ }^{1}$ These challenges include inconsistencies in voice and a lack of sufficient or dedicated resources for library website management, resulting in the absence of shared strategic vision and organizational unity regarding the purpose and function of the library website. We concluded that a productive solution to these challenges lay in the inherently user-centered practice of web content strategy, defined as "an emerging discipline that brings together concepts from user experience design, information architecture, marketing, and technical writing." 2

We further noted that organizational support for web content management and governance strategies for library-authored web content had been rarely addressed in the library literature, despite the growing importance of this area of expertise to the successful provision of support and services: "Libraries must proactively embrace and employ best practices in content strategy ... to fully realize the promise of content management systems through embracing an ethos of libraryauthored content."3

We now investigate the current state of practice and philosophy around the creation, editing, management, and evaluation of library-authored web content. To what degree, if at all, does web content strategy factor into the actions, policies, and practices of academic libraries, and academic librarians today? Does a suitable measure for estimating the maturity of web content strategy practice for academic libraries exist?

Courtney McDonald (crmcdonald@colorado.edu) is Associate Professor and User Experience Librarian, University of Colorado Boulder. Heidi Burkhardt (heidisb@umich.edu) is Web Project Manager and Content Strategist, University of Michigan. (C) 2021. 


\section{BACKGROUND}

\section{Maturity Models}

Maturity models are one useful mechanism for consistently measuring and assessing an organization's current level of achievement in a particular area, as well as providing a path to guide future growth and improvement: "Maturity levels represent a staged path for an organization's performance and process improvement efforts based on predefined sets of practice areas.... Each maturity level builds on the previous maturity levels by adding new functionality or rigor." 4 The initial work on maturity models emerged from Carnegie Mellon Institute (CMI), focused on contract software development. ${ }^{5}$ Since that time, CMI founded the CMMI Institute which has expanded the scope of maturity models into other disciplines.

Many such models, developed for a variety of specific industries or specializations, have since been developed based on the CMMI Institute approach, in which stages are defined as:

- Maturity Level 1: Initial (unpredictable and reactive);

- Maturity Level 2: Managed (planning, performance, measurement and control occur on the project level);

- Maturity Level 3: Defined (proactive, rather than reactive, with organization-wide standards);

- Maturity Level 4: Quantitatively Managed (data-driven with shared, predictable, quantitative performance improvement objectives that align to meet the needs of internal and external stakeholders); and

- Maturity Level 5: Optimizing (Stable, flexible, agile, responsive, and focused on continuous improvement). ${ }^{6}$

\section{Application of Maturity Models Within User Experience Work in Libraries}

Thus far, discussion of maturity models in the library literature relevant to web librarianship has primarily centered on user experience (UX) work. In their 2020 paper "User Experience Methods and Maturity in Academic Libraries," Young, Chao, and Chandler noted, "... several different UX maturity models have been advanced in recent years," reviewing approximately a half-dozen approaches with varying emphases and numbers of stages. ${ }^{7}$

In 2013, Coral Sheldon-Hess developed the following five-stage model, based on the aforementioned CMMI framework, for assessing maturity of UX practice in library organizations:

1 - Decisions are made based on staff's preferences, management's pet projects. User experience [of patrons] is rarely discussed.

2 - Some effort is made toward improving the user experience. Decisions are based on staff's gut feelings about patrons' needs, perhaps combined with anecdotes from service points.

3 - The organization cares about user experience; one or two UX champions bring up users' needs regularly. Decisions are made based on established usability principles and studies from other organizations, with occasional usability testing. 
4 - User experience is a primary motivator; most staff are comfortable with UX principles. Users are consulted regularly, not just for major decisions, but in an ongoing attempt at improvement.

5 - User experience is so ingrained that staff consider the usability of all of their work products, including internal communications. Staff are actively considerate, not only toward users but toward their coworkers. ${ }^{8}$

As an indicator of overall UX maturity within an organization, Sheldon-Hess focuses on "consideration" in interactions not only between library staff and library patrons, but also between library staff: "When an organization is well and truly steeped in UX, with total awareness of and buy-in on user-centered thinking, its staff enact those principles, whether they're facing patrons or not."9

In 2017, MacDonald conducted a series of semi-structured interviews with 16 UX librarians to investigate, among other things, "the organizational aspects of UX librarianship across various library contexts." ${ }^{10}$ MacDonald proposes a five-stage model, broadly similar in concept to the CMMI Institute structure and to Sheldon-Hess's model. Most compelling, however, were these three major findings, taken from MacDonald's list:

- Some (but not all) UX librarian positions were created as part of purposeful and strategic efforts to be more self-aware; ... .

- the biggest challenges to doing UX are navigating the complex library culture, balancing competing responsibilities, and finding ways to more efficiently employ UX methods; and

- the level of co-worker awareness of UX librarianship is driven by the extent to which UX work is visible and by the individual UX librarian's ability to effectively communicate their role and value. ${ }^{11}$

Based on analysis of the results of their 2020 survey of library UX professionals, in which they asked respondents to self-diagnose their organizations, Young, Chao, and Chandler presented, for use in libraries, their adaptation of the Nielsen Norman Group's eight-stage scale of UX maturity:

- Stage 1: Hostility Toward Usability / Stage 2: Developer-Centered UX-Apathy or hostility to UX practice; lack of resources and staff for UX.

- Stage 3: Skunkworks UX-Ad hoc UX practices within the organization; UX is practiced, but unofficially and without dedicated resources or staff; leadership does not fully understand or support UX. ${ }^{12}$

- Stage 4: Dedicated UX Budget-Leadership beginning to understand and support UX; dedicated UX budget; UX is assigned fully or partly to a permanent position.

- Stage 5: Managed Usability-The UX lead or UX group collaborates with units across the organization and contributes UX data meaningfully to organizational and strategic decision-making.

- Stage 6: Systematic User-Centered Design Process-UX research data is regularly included in projects and decision-making; a wide variety of methods are practiced regularly by multiple departments.

- Stage 7: Integrated User-Centered Design / Stage 8: User-Driven Organization-UX is practiced throughout the organization; decisions are made and resources are allocated only with UX insights as a guide. ${ }^{13}$ 
Young et al.'s findings supported MacDonald's, underscoring the importance of shared organizational understandings, priorities, and culture related to UX activities and personnel:

UX maturity in libraries is related to four key factors: the number of UX methods currently in use; the level of support from leadership in the form of strategic alignment, budget, and personnel; the extent of collaboration throughout the organization; and the degree to which organizational decisions are influenced by UX research. When one or more of these four connected factors advances, so too does UX maturity. ${ }^{14}$

These findings are consistent with larger patterns in the management of library-authored web content identified in the earlier cited literature review:

Inconsistent processes, disconnects between units, varying constituent goals, and vague or ineffective WCM governance structures are recurrent themes throughout the literature ... web content governance issues often signal a lack of coordination, or even of unity, across an organization. ${ }^{15}$

\section{Assessing the Maturity of Content Strategy Practice in Libraries}

We consider Kristina Halverson's definition of content strategy, offered in Content Strategy for the $W e b$, as the authoritative definition. Halverson states: "Content strategy is the practice of planning for the creation, delivery, and governance of useful, usable content."16

This definition can be divided into five elements:

1. Planning: intentionality and alignment, setting goals, discovery and auditing, connecting to strategic a plan or vision

2. Creation: roles, responsibilities, and workflows for content creation; attention to content structure; writing or otherwise developing content in its respective format

3. Delivery: findability of content within site and more broadly (i.e., search engine optimization), use of distinct communication channels

4. Governance: maintenance and lifecycle management of content through coordinated process and decision making; policies and procedures; measurement and evaluation through analysis of usage data, testing, and other means

5. Useful/Usable (hereafter referred to as UX): relevant, current, clear, concise, and in context

Jones discusses the application of content strategy-specific maturity models as a potential tool for content strategists: "The[se] model[s] can help your company identify your current level of content operations, ... decide whether that level will support your content vision and strategy ... [and] help you plan to get to the next level of content operations." 17 Three examples of maturity models developed for use by content strategy industry professionals map industry-specific terms, tools, and actions to the level-based structure put forward by the CMMI Institute (see table 1). 
Table 1. Comparative table of content strategy maturity models

\begin{tabular}{|c|c|c|}
\hline $\begin{array}{l}\text { Content Strategy, Inc. }{ }^{18} \\
{[2016]}\end{array}$ & $\begin{array}{l}\text { Jones (GatherContent) } \\
\text { [2018] }\end{array}$ & Randolph (Kapost) ${ }^{20}[2020]$ \\
\hline $\begin{array}{l}\text { Ad hoc: Inconsistent quality, } \\
\text { lack of uniform practice, little } \\
\text { or no opportunity to } \\
\text { understand customer needs }\end{array}$ & $\begin{array}{l}\text { Chaotic: No formal content } \\
\text { operations, only ad hoc } \\
\text { approaches }\end{array}$ & $\begin{array}{l}\text { Reactive: Chaotic, siloed, } \\
\text { lacking clarity, chronically } \\
\text { behind }\end{array}$ \\
\hline $\begin{array}{l}\text { Rudimentary: Movement } \\
\text { toward structure, unified } \\
\text { process and voice; can be } \\
\text { derailed by timelines, } \\
\text { resistance }\end{array}$ & $\begin{array}{l}\text { Piloting: Trying content } \\
\text { operations in certain areas, } \\
\text { such as for a blog }\end{array}$ & $\begin{array}{l}\text { Siloed: Struggles to } \\
\text { collaborate, poorly defined } \\
\text { and inconsistently measured } \\
\text { goals }\end{array}$ \\
\hline $\begin{array}{l}\text { Organized \& Repeatable: } \\
\text { strong leadership, uniform } \\
\text { process and voice has become } \\
\text { routine, integration of user- } \\
\text { focused data collection }\end{array}$ & $\begin{array}{l}\text { Scaling: Expanding formal } \\
\text { content operations across } \\
\text { business functions }\end{array}$ & $\begin{array}{l}\text { Mobilizing: Varying } \\
\text { collaboration, content is } \\
\text { centralized but not necessarily } \\
\text { accessible, defined strategy } \\
\text { sometimes impacted by ad hoc } \\
\text { requests }\end{array}$ \\
\hline $\begin{array}{l}\text { Managed \& Sustainable: larger } \\
\text { buy-in across organization, } \\
\text { can sustain changes in } \\
\text { leadership, increased number } \\
\text { and sophistication of methods }\end{array}$ & $\begin{array}{l}\text { Sustaining: Solidifying and } \\
\text { optimizing content operations } \\
\text { across business functions }\end{array}$ & $\begin{array}{l}\text { Integrating: Effective } \\
\text { collaboration across multiple } \\
\text { teams, capability for proactive } \\
\text { steps, still struggle to prove } \\
\text { ROI }\end{array}$ \\
\hline $\begin{array}{l}\text { Optimized: close alignment to } \\
\text { strategic objectives, } \\
\text { integration across the } \\
\text { organization, leadership } \\
\text { within and outside the } \\
\text { organization }\end{array}$ & $\begin{array}{l}\text { Thriving: Sustaining while also } \\
\text { innovating and seeing return } \\
\text { on investment (ROI) }\end{array}$ & $\begin{array}{l}\text { Optimizing: Cross-functional } \\
\text { collaboration results in } \\
\text { seamless customer messaging } \\
\text { and experiences, consistently } \\
\text { measured ROI contributes to } \\
\text { planning }\end{array}$ \\
\hline
\end{tabular}

While these models have some utility for content strategy practitioners in higher education, including those in academic and research libraries, emphasis on commercial standards for assessing success (e.g., business goals, centrally managed marketing) limits their direct application in the academic environment. The 2017 blog post by Tracey Playle, "Ten Pillars for Getting the Most of Your Content: How is Your University Doing?", presented ten concepts paired with questions, which could be used by higher education content professionals to reflect on their current state of practice. ${ }^{21}$ This model was developed for use by a consultancy, and the "pillars"-"strategy and vision," "risk tolerance and creativity," and "training and professional development" - are more broadly conceived than typical maturity models. Thus, this approach seems more appropriate as a personal or management planning tool rather than as a model for evaluating maturity across library organizations. 


\section{METHODS}

Following review and approval by the researchers' institutional review boards, a web-based survey collecting information about existing workflows for web content, basic organizational information, and familiarity with concepts related to web content strategy was distributed to 208 professionals in April 2020. The survey was available for four weeks. Participants were drawn from academic and research libraries across North America, providing their own opinions as well as information on behalf of their library organization. (See Appendix A: Institution List.)

The sample group $(n=208)$ was composed of North American academic and research libraries that are members of the following nationally and regionally significant membership organizations (excluding non-academic member institutions): the Association of Research Libraries, the Big Ten Academic Alliance, the Greater Western Library Alliance, and/or the Oberlin Group. Some libraries are members of multiple groups. Details are supplied below in table 3.

We identified individuals $(n=165)$ based on their professional responsibilities and expertise using the following order and process:

1. Individual job title contains some combinations of the following words and/or phrases: content strategy, content specialist, content strategist, web content, web communications, digital communications, digital content

2. Head of web department or department email

3. Head of UX department or department email

4. Head of IT or department email

For institutions where a specific named individual could not be identified through a review of the organizational website, we identified a general email (e.g., libraries@state.edu) as the contact $(n=43)$.

A mailing list was created in MailChimp, and two campaigns were created: one for named individuals, and one for general contacts. Only one response was requested per institution. (See Appendix B: Recruitment Emails.) The 165 named individuals, identified as described above, received a personalized email inviting them to participate in the study. The recruitment email explained the purpose of the study, advised potential participants of possible risks and their ability to withdraw at any time, and included a link to the survey. A separate email was sent to the 43 general contacts on the same day, explaining the purpose of the study, and requesting that the recipient forward the communication to the appropriate person in the organization. This email also included information advising potential participants of possible risks and their ability to withdraw at any time, and a link to the survey.

Data was recorded directly by participants using Qualtrics. The bulk of survey data does not include any personal information; we did not collect the names of institutions as part of our data collection, so identifying information is limited to information about institutional memberships.

For the group of named individuals, one email bounce was recorded. The open rate for personalized emails sent to named individuals was approximately 62\% (88 of 142 successfully delivered emails were opened) and the survey link was followed 66 times. The general email group had a $51 \%$ open rate $(n=22)$ with 11 clicks of the survey link. With recruitment occurring in April 2020, most individuals and institutions were at the height of switching to remote operations 
in light of the COVID-19 pandemic. Despite this, our open rates were considerably higher than average open rates as reported by Mailchimp. ${ }^{22}$ As discussed below, we achieved our minimum response rate goal of $20 \%$.

Table 2. Survey question topics and response count

\begin{tabular}{|c|c|c|c|}
\hline Question & Topic & Category & Response Count \\
\hline 1 & Consent & - & 43 \\
\hline 2 & Organizational memberships & Demographic & 40 \\
\hline 3 & Approx. \# full-time employees & Demographic & 41 \\
\hline 4 & CMS products used & $\begin{array}{l}\text { Infrastructure/ } \\
\text { Organizational Structure }\end{array}$ & 41 \\
\hline 5 & Primary CMS & $\begin{array}{l}\text { Infrastructure/ } \\
\text { Organizational Structure }\end{array}$ & 39 \\
\hline 6 & Number of site editors & $\begin{array}{l}\text { Infrastructure/ } \\
\text { Organizational Structure }\end{array}$ & 39 \\
\hline 7 & Describe responsibility for content & $\begin{array}{l}\text { Infrastructure/ } \\
\text { Organizational Structure }\end{array}$ & 39 \\
\hline 8 & $\begin{array}{l}\text { Existence of position(s) with } \\
\text { primary duties of web content }\end{array}$ & $\begin{array}{l}\text { Infrastructure/ } \\
\text { Organizational Structure }\end{array}$ & 39 \\
\hline 9 & Titles of such positions, if any & $\begin{array}{l}\text { Infrastructure/ } \\
\text { Organizational Structure }\end{array}$ & 24 \\
\hline 10 & Familiar with web content strategy & Content Strategy Practices & 36 \\
\hline 11 & Definition of web content strategy & Content Strategy Practices & 32 \\
\hline 12 & Policies or documentation & Content Strategy Practices & 35 \\
\hline 13 & Methods & Content Strategy Practices & 37 \\
\hline 14 & Willing to be contacted & - & 37 \\
\hline 15 & Name & - & 27 \\
\hline 16 & Email & - & 26 \\
\hline
\end{tabular}

The survey included 16 questions; question topics and response counts are noted in table 2. Informed consent was obtained as part of the first survey question. (See Appendix C: Survey Questions and Appendix D: Informed Consent Document.) Most questions were multiple-choice or short answer (i.e., a number). Two questions required longer-form responses. Information collected fell into the following three categories: 
- Demographics (estimated total number of employees; institutional memberships; estimated number of employees with website editing privileges)

- Infrastructure and organizational structure (content management systems used to manage library-authored web content; system used to host primary public-facing website; distribution of responsibility for website content; titles of positions (if any) whose primary responsibilities focus on web content)

- Web content strategy practices (familiarity with; personal definition; presence or absence of policy or documentation; evaluation methods regularly used)

Upon completion of the survey questions, participants had the option to indicate that they would be willing to be contacted for an individual interview as part of planned future research on this topic. Twenty-seven individuals (63\%) opted in and provided us with their contact information.

\section{FINDINGS}

In sum, 43 responses were received, resulting in a response rate of $20.67 \%$. Because we did not collect names of individuals or institutions and used an anonymous link for our survey, we cannot determine the ultimate response rate by contact group (named individuals or general email).

\section{Demographic Information}

The bulk of responses came from Association of Research Libraries members, but within-group response rates show that the proportion of responses from each group was relatively balanced within the overall $20 \%$ response rate.

Table 3. Distribution of survey contacts, responses, and response rates by group ${ }^{23}$

\begin{tabular}{|l|r|r|r|c|}
\hline Organization & $\begin{array}{c}\text { Member } \\
\text { Libraries } \\
\text { Contacted }\end{array}$ & Responses & $\begin{array}{c}\text { Share of } \\
\text { Total } \\
\text { Responses } \\
\mathbf{( \% )}\end{array}$ & $\begin{array}{c}\text { Group } \\
\text { Response } \\
\text { Rate (\%) }\end{array}$ \\
\hline Association of Research Libraries & 117 & 26 & 50.98 & 22.22 \\
\hline Big Ten Academic Alliance & 15 & 5 & 9.8 & 33.0 \\
\hline Greater Western Library Alliance & 38 & 8 & 15.69 & 21.05 \\
\hline Oberlin Group & 80 & 12 & 23.53 & 15.0 \\
\hline
\end{tabular}

\section{Infrastructure \& Organizational Structure}

Content Management Systems

A variety of content management systems are used to manage library-authored web content (see table 4); LibGuides, WordPress, Omeka, and Drupal were most commonly used across the group. Other systems mentioned as write-in responses included Acquia Drupal, Cascade, Fedora-based systems, ArchivesSpace, Google Sites, and "wiki and blog." One response stated, "Most pages are just Non-CMS for the website." Write-in responses for "Other" and "Proprietary system hosted by institution" were carried forward within the survey from question 3 to question 4, and are available in full in Appendix E: Other Content Management Systems Mentioned by Respondents. 
Table 4. CMS products used to manage library-authored web content

\begin{tabular}{|l|c|r|}
\hline Q3: CMS products used & $\begin{array}{c}\text { Percentage } \\
(\mathbf{\% )}\end{array}$ & Count \\
\hline LibGuides & 28.06 & 39 \\
\hline WordPress & 18.71 & 26 \\
\hline Omeka & 15.11 & 19 \\
\hline Drupal & 13.67 & 13 \\
\hline Other & 9.35 & 10 \\
\hline Sharepoint & 7.19 & 10 \\
\hline $\begin{array}{l}\text { Proprietary system hosted by } \\
\text { institution }\end{array}$ & 7.19 & 1 \\
\hline Adobe Experience Manager & 0.72 & $\mathbf{1 3 9}$ \\
\hline Total & $\mathbf{1 0 0}$ & \\
\hline
\end{tabular}

For their primary library website, just under half of respondents relied on Drupal $(n=17,43.59 \%)$. Slightly fewer selected the specific system, whether the institution's proprietary system or some other option, that they had shared as a write-in answer for the previous question; in total just under 36\% (n=14). Despite the widespread use reported in the previous question, only two respondents indicated that their primary website was hosted in LibGuides. (See table 5.)

Table 5. CMS used to host primary library website

\begin{tabular}{|l|c|r|}
\hline Q4: primary website CMS & $\begin{array}{c}\text { Percentage } \\
\text { (\%) }\end{array}$ & Count \\
\hline Drupal & 43.59 & 17 \\
\hline Other (write in answers) & 20.51 & 8 \\
\hline WordPress & 15.38 & 6 \\
\hline LibGuides & 5.13 & 2 \\
\hline $\begin{array}{l}\text { Proprietary system hosted by institution } \\
\text { (write in answers) }\end{array}$ & 15.38 & 6 \\
\hline
\end{tabular}

Dedicated Positions, Position Titles, and Organizational Workflows

Almost two-thirds of respondents $(n=24,61.5 \%)$ indicated there were position(s) within their library whose primary duties were focused on the creation, management, and/or editing of web content. A total of 52 position titles were shared (the full list of position titles can be found in Appendix F). Terms and phrases most commonly occurring across this set were web (15), librarian (15), user experience (10), and digital (8). Explicitly content-focused terms appeared more rarely: content (6), communication/communications (5), and editor (1). 
Table 6. Frequency of terms and phrases in free-text descriptions of website content management, grouped by the authors into concepts

\begin{tabular}{|c|c|c|c|c|c|c|c|c|c|c|}
\hline & & Count & & Count & & Count & & Count & & Count \\
\hline Concept & Collaborative & 29 & $\begin{array}{l}\text { Assigned } \\
\text { roles }\end{array}$ & 18 & $\begin{array}{l}\text { Locus of } \\
\text { control }\end{array}$ & 13 & Support & 5 & \multirow[t]{6}{*}{ LibGuides } & \multirow[t]{6}{*}{14} \\
\hline & team & 6 & manager & 5 & review & 3 & guidance & 2 & & \\
\hline & distributed & 5 & editor/s & 4 & oversight & 3 & consulting & 1 & & \\
\hline & stakeholder & 3 & $\begin{array}{l}\text { product } \\
\text { owner }\end{array}$ & 2 & & & & & & \\
\hline & representative & 2 & & & & & & & & \\
\hline & $\begin{array}{l}\text { cross- } \\
\text { departmental }\end{array}$ & 1 & & & & & & & & \\
\hline
\end{tabular}


Most respondents described collaborative workflows for web content management, in which a group of representatives or delegates collectively stewards website content (see table 6 for a summary and Appendix F for full-text responses). Collaborative concepts appeared 29 times, including terms like group (7), team (6), distributed (5), and committee (3). Within this set, decentralized, inclusive, and cross-departmental each appeared once. Similarly, within terms related to locus of control, the phrase "their own" appeared seven times. Specifically assigned roles or responsibilities were mentioned 18 times, including terms like admin/administrator (6), manager (5), and editor/s or editorial (4). Respondents discussed support structures such as training, guidance or consulting five times. LibGuides were mentioned 14 times.

Over $60 \%$ of respondents indicated that 20 or fewer employees had editing privileges on the library website (see table 7). Three respondents commented "too many" when citing the number or range: "Too many! I think about five, but there could be more"; "too many, about 12"; "Too many to count, maybe $20+. "$

Table 7. Distribution of the number of employees with website editing privileges

\begin{tabular}{|l|c|r|}
\hline Response & $\begin{array}{c}\text { Percentage } \\
\text { (\%) }\end{array}$ & Count \\
\hline Less than five & 23.08 & 9 \\
\hline $5-10$ & 20.51 & 8 \\
\hline $11-20$ & 17.95 & 7 \\
\hline $21-99$ & 23.08 & 9 \\
\hline $100-199$ & 10.26 & 4 \\
\hline $200+$ & 2.56 & 1 \\
\hline
\end{tabular}

The greatest variation in practice regarding how many employees had website editing privileges occurs in institutions with more than 100 total employees, where institutions reported within every available range (see table 8 ).

Table 8. Comparison of number of total employees and of number of employees with editing privileges

\begin{tabular}{|l|c|c|c|c|c|c|}
\hline $\begin{array}{l}\text { Number of } \\
\text { Employees }\end{array}$ & Less than 5 & $\mathbf{5 - 1 0}$ & $\mathbf{1 1 - 2 0}$ & $\mathbf{2 1 - 9 9}$ & $\mathbf{1 0 0 - 1 9 9}$ & $\mathbf{2 0 0 +}$ \\
\hline $4-10$ & 2 & - & - & - & - & - \\
\hline $11-25$ & 3 & 1 & - & - & - & - \\
\hline $26-50$ & - & 2 & 2 & - & - & - \\
\hline $51-99$ & 1 & 1 & 4 & 1 & - & - \\
\hline $100+$ & 3 & 4 & 2 & 8 & 4 & 1 \\
\hline
\end{tabular}




\section{Web content strategy practices}

Almost all respondents $(n=36,83 \%)$ reported that they were familiar with the concept of web content strategy. Conversely, only $20 \%(n=7)$ reported that their library had either a documented web content strategy or web content governance policy. Respondents were asked, optionally, to provide a definition of web content strategy in their own words, and we received 32 responses (see Appendix G: Definitions of Web Content Strategy).

We analyzed the free-text definitions of content strategy based on the five elements of Halvorson's previously cited definition: planning, creation, delivery, governance, and UX. We first individually rated the definitions, then we determined a mutually agreed rating for each. Across the set, responses most commonly addressed concepts or activities related to planning and UX, and least commonly mentioned concepts or activities related to delivery (see table 9).

Table 9. Occurrence of content strategy elements in free-text definitions

\begin{tabular}{|l|r|c|}
\hline Element & Count & $\begin{array}{c}\text { Percentage } \\
\text { (\%) }\end{array}$ \\
\hline $\begin{array}{l}\text { Plan } \\
\text { intentional, strategic, brand, style, } \\
\text { best practices }\end{array}$ & 29 & 91 \\
\hline $\begin{array}{l}\text { Creation } \\
\text { workflows, structure, writing }\end{array}$ & 20 & 63 \\
\hline $\begin{array}{l}\text { Delivery } \\
\text { findability, channels }\end{array}$ & 13 & 41 \\
\hline $\begin{array}{l}\text { Governance } \\
\text { maintenance, lifecycle, } \\
\text { measurement/evaluation }\end{array}$ & 16 & 50 \\
\hline $\begin{array}{l}\text { UX } \\
\text { needs of the user, relevant, } \\
\text { current, clear, concise, in context }\end{array}$ & 19 & 59.38 \\
\hline
\end{tabular}

Responses were scored on each of the five elements as follows: zero points, concept not mentioned; one point, some coverage of the concept; two points, thorough coverage of the concept. Representative examples are provided in table 10. A perfect score for any individual definition would be 10 . The median score across the group was four, and the average score was 3.4.

We consider scores less than three to indicate a basic level of practice; scores from four to seven to be an intermediate level of practice; and scores above eight to be advanced levels of practice. Of the 33 responses to the free-text definition question, one respondent failed to include any data, 14 responses were classed as basic, 17 responses as intermediate, and none were advanced. 
Table 10. Example showing scoring of four representative free-text definitions provided by respondents

\begin{tabular}{|c|c|c|c|c|c|c|}
\hline $\begin{array}{l}\text { Free-text definitions of content } \\
\text { strategy }\end{array}$ & $\begin{array}{l}\text { Plan } \\
\text { intentional, } \\
\text { strategic, } \\
\text { brand, style, } \\
\text { best } \\
\text { practices }\end{array}$ & $\begin{array}{l}\text { Creation } \\
\text { workflows, } \\
\text { structure, } \\
\text { writing }\end{array}$ & $\begin{array}{l}\text { Delivery } \\
\text { findability, } \\
\text { channels }\end{array}$ & $\begin{array}{l}\text { Governance } \\
\text { maintenance, } \\
\text { lifecycle, } \\
\text { measuremen } \\
\text { t/evaluation } \\
\end{array}$ & $\begin{array}{l}\text { UX } \\
\text { needs of the } \\
\text { user, } \\
\text { relevant, } \\
\text { current, } \\
\text { clear, } \\
\text { concise, and } \\
\text { in context } \\
\end{array}$ & Total Score \\
\hline $\begin{array}{l}\text { Intentional and coordinated } \\
\text { vision for content on the website. }\end{array}$ & 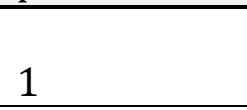 & 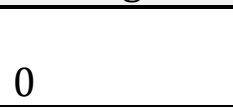 & 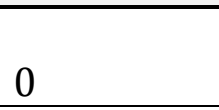 & r & 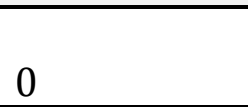 & 1 \\
\hline $\begin{array}{l}\text { An overarching method of } \\
\text { bringing user experience best } \\
\text { practices together on the website } \\
\text { including heuristics, information } \\
\text { architecture, and writing for the } \\
\text { web. }\end{array}$ & 1 & 1 & 0 & 0 & 1 & 3 \\
\hline $\begin{array}{l}\text { Strategies for management of } \\
\text { content over its entire lifecycle to } \\
\text { ensure it is accurate, timely, } \\
\text { usable, accessible, appropriate, } \\
\text { findable, and well-organized. }\end{array}$ & 1 & 0 & 1 & 1 & 1 & 4 \\
\hline $\begin{array}{l}\text { The process of creating and } \\
\text { enacting a vision for the } \\
\text { organization and display of web } \\
\text { content so that it is user friendly, } \\
\text { accurate, up-to-date, and effective } \\
\text { in its message. Web content } \\
\text { strategy often involves } \\
\text { considering the thoughts and } \\
\text { needs of many stakeholders, and } \\
\text { creating one cohesive voice to } \\
\text { represent them all. }\end{array}$ & 2 & 1 & 0 & 1 & 2 & 6 \\
\hline
\end{tabular}


Respondents reported most frequent use of practices associated with web librarianship and user experience work: analysis of usage data $(n=36)$ and usability testing $(n=28)$ (see fig. 1). Contentspecific methods were less commonly used overall.

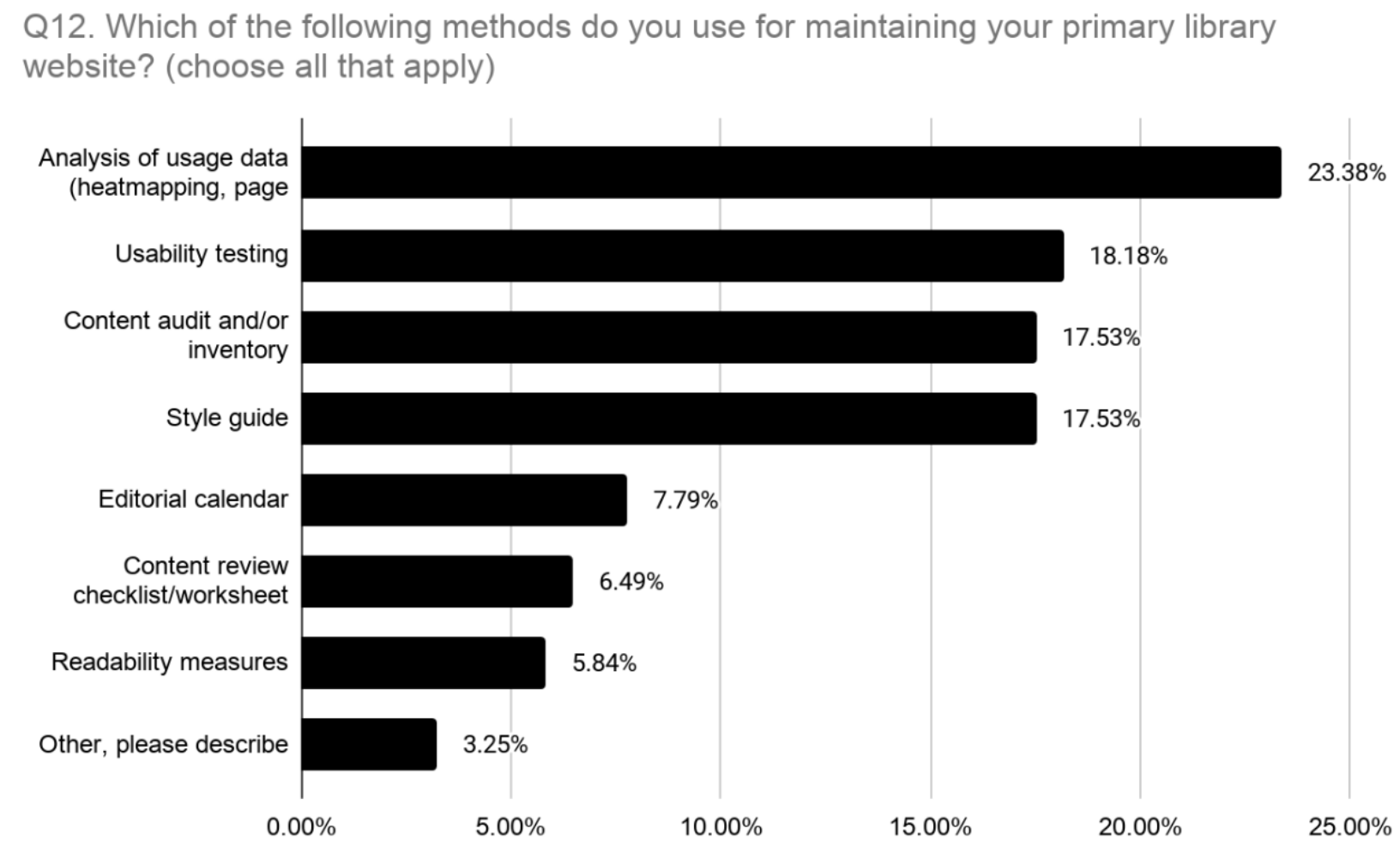

Figure 1. Frequency of reported usage of analysis and evaluation methods

The five Other responses mainly clarified or qualified the selections, although some added additional information, for example:

At this time, all library websites use a standard template, so they have the same look and feel. Beyond that everything else is "catch as catch can" because we do not have a web services librarian, nor are we likely to get that dedicated position any time soon, given the recent COVID-19 financial upheaval.

Brand guidelines, accessibility guidance, and personal responsibility were also mentioned.

\section{DISCUSSION}

The targeted recruitment methodology and survey, representing a combination of demographic and practice-based questions, aspired to collect data suitable to generate a snapshot of how web content strategy work is being undertaken in academic libraries at this time, as well as the depth and breadth of that practice.

We were struck by several contrasts in findings: first and foremost, the 80-20 inversion across responses related to knowledge of web content strategy versus its practice. This was particularly notable in combination with respondents' reports that, in nearly two-thirds of organizations, one 
or multiple positions exist in their organization with primary duties focused on the creation, management, and/or editing of web content.

The influence of UX thinking and methods in academic libraries is visible in the frequency of respondents' reported use of general and established UX practices for maintaining the primary website (e.g., usability testing). The other four elements of Halvorson's definition were less thoroughly covered, both in provided definitions of web content strategy and in methods reported. Some respondents mentioned use of methods such as content audits or inventories and style guides, but many fewer reported reliance on review checklists, content calendars, and readability scores.

In reviewing the self-reported definitions of content strategy for evidence of each of the five elements of Halvorson's previously discussed definition, trends in findings suggest higher levels of maturity in the elements of planning, creation, and UX, and lower levels in the elements of delivery and governance. Nearly all respondents (91\%) referenced the element of planning. Almost twothirds mentioned concepts or practices related to creation, and approximately $60 \%$ of respondents referenced usability of content or a focus on the user in some capacity. Only half made mention of governance (including maintenance and evaluation), and even fewer (41\%) referenced delivery, whether considering content channels or findability; in fact, no single definition touched on both. Overall, the results of the analysis of provided definitions (discussed in the previous section) suggest that at present, web content strategy as a community of practice in academic libraries is operating at, or just above, a basic level.

\section{Proposed Maturity Model}

From these findings, and referencing the structure of the CMMI Institute five-stage maturity model, the authors propose the following proposed Content Strategy Maturity Model for Academic Libraries.

As previously noted in our findings, we assess the web content strategy community of practice in academic libraries as operating at, or just above, a basic level. To align the proposed maturity model with the definition scores, we applied the 10-point rating scale for provided definitions to the five levels by assigning two points per level, so a score of one or two would be equivalent to Level 1, a score of three or four equivalent to Level 2, and so on (table 11).

Table 11. Comparison of maturity model with definition rating scale and maturity assessment

\begin{tabular}{|l|r|l|}
\hline Maturity model level & Definition score & Assessment \\
\hline Level 1 & 1 & Basic \\
\cline { 1 - 2 } Level 1 & 2 & Basic \\
\cline { 1 - 2 } Level 2 & 3 & Basic \\
\hline Level 2 & 4 & Intermediate \\
\cline { 1 - 2 } Level 3 & 5 & Intermediate \\
\cline { 1 - 2 } Level 3 & 6 & Intermediate \\
\cline { 1 - 2 } Level 4 & 7 & Intermediate \\
\hline Level 4 & 8 & Advanced \\
\cline { 1 - 2 } Level 5 & 9 & Advanced \\
Level 5 & 10 & Advanced \\
\cline { 1 - 2 } & \multicolumn{2}{|r}{}
\end{tabular}




\section{CONTENT STRATEGY MATURITY MODEL FOR ACADEMIC LIBRARIES}

\section{Level 1: Ad hoc}

- No planning or governance

- Creation and delivery are reactive, distributed, and potentially chaotic

- No or minimal consideration of UX

\section{Level 2: Establishing}

- Some planning and evidence of strategy, such as use of content audits and creation of a style guide; may be localized within specific groups or units

- Basic coordination of content creation workflows

- Delivery workflows not explicitly addressed, or remain haphazard

- No or minimal organization-wide governance structures or documentation in place; may be localized within specific groups or units

- Evidence of active consideration of UX in creation and structure of content

\section{Level 3: Scaling}

- Intentional and proactive planning coordinated across multiple units

- Basic content creation workflows in place across organization

- Delivery considered, but may not be consistent or strategic

- Ad hoc evaluation through usage data and usability testing; organization-wide governance documents and workflows may be at a foundational level

- Consideration of UX is integral to process of creating useful, usable content

- Web content creation and maintenance is assigned at least partly to a permanent position with some level of authority and responsibility for the primary website

\section{Level 4: Sustaining}

- Alignment in planning, able to respond to organizational priorities; style guidelines and best practices widely accepted

- Established and accepted workflows for content creation are coordinated through a person, department, team, or other governing body

- Delivery includes strategic and consistent use of channels, as well as consideration of findability

- Regular and strategic evaluation occurs; proactive maintenance and retirement practices in place; managed through established governance documents and workflows

- Web content strategy explicitly assigned partly or fully to a permanent position

\section{Level 5: Thriving}

- Full lifecycle of content (planning, creation, delivery, maintenance, retirement) managed in coordination across all library-authored web content platforms

- Governance established and accepted throughout the organization, including documented policies, procedures, and accountability

- Basic understanding of content strategy concepts and importance across the organization

- Overall stable, flexible, agile, responsive, user-centered and focused on continuous improvement 
As previously mentioned, the median score across the group was four, and the average score was 3.4; these measures suggest that the majority of survey respondents' organizational web content strategy maturity levels would currently stand at level 2 or 3 , with a few at level 1 .

\section{CONCLUSION}

The findings of this survey and assessment, while inherently limited, suggest that web content strategy is currently not a pervasive factor for academic libraries and academic web librarians in the development and implementation of actions, policies, and practices related to website creation, maintenance, and evaluation.

We have proposed a measure for self-estimating the maturity of web content strategy practice for academic libraries. Our Content Strategy Maturity Model for Academic Libraries, while grounded both in industry best practices and in evidence from practitioners in academic libraries, is nonetheless a work in progress. We intend to further develop and strengthen the model through follow-up interviews with practitioners, drawing on those survey respondents who opted-in to being contacted. Interviewees will be invited to discuss their work within and outside the frame of the proposed maturity model, and to provide feedback on the model itself, with the ultimate goal of enabling a better understanding of web content strategy practice in academic libraries and the needs of its community of practice.

\section{ENDNOTES}

${ }^{1}$ Courtney McDonald and Heidi Burkhardt, "Library-Authored Web Content and the Need for Content Strategy," Information Technology and Libraries 38, no. 3 (September 15, 2019): 8-21, https://doi.org/10.6017/ital.v38i3.11015.

${ }^{2}$ McDonald and Burkhardt, 14.

${ }^{3}$ McDonald and Burkhardt, 16.

4 "CMMI Levels of Capability and Performance," sec. Maturity Levels, CMMI Institute LLC, accessed May 28 2020, https://cmmiinstitute.com/learning/appraisals/levels.

5 “About CMMI Institute," CMMI Institute LLC, accessed May 28 2020, https://cmmiinstitute.com/company.

6 "CMMI Levels of Capability and Performance," sec. Maturity Levels.

${ }^{7}$ Scott W. H. Young, Zoe Chao, and Adam Chandler, "User Experience Methods and Maturity in Academic Libraries," Information Technology and Libraries 39, no. 1 (March 16, 2020): 2, https://doi.org/10.6017/ital.v39i1.11787.

${ }^{8}$ Coral Sheldon-Hess, "UX, Consideration, and a CMMI-Based Model," para. 6, July 25, 2013, http://www.sheldon-hess.org/coral/2013/07/ux-consideration-cmmi/.

${ }^{9}$ Sheldon-Hess, "UX, Consideration, and a CMMI-Based Model," para. 2, http://www.sheldonhess.org/coral/2013/07/ux-consideration-cmmi/. 
${ }^{10}$ Craig M. MacDonald, “'It Takes a Village': On UX Librarianship and Building UX Capacity in Libraries," Journal of Library Administration 57, no. 2 (February 17, 2017): 196, https://doi.org/10.1080/01930826.2016.1232942.

${ }^{11}$ MacDonald, 212.

12 SKUNK WORKS is trademarked by Lockheed Martin Corporation, but is informally used to describe an experimental, sometimes secret, research and development group focused on agile innovation.

13 Young, Chao, and Chandler, “User Experience Methods and Maturity in Academic Libraries,” 19.

14 Young, Chao, and Chandler, 23.

15 McDonald and Burkhardt, "Library-Authored Web Content and the Need for Content Strategy," 15-16.

${ }^{16}$ Kristina Halvorson, Content Strategy for the Web, 2nd ed. (Berkeley, CA: New Riders, 2012), 28.

${ }^{17}$ Colleen Jones, "A Content Operations Maturity Model," sec. A maturity model for content operations, Gather Content (blog), November 30, 2018, https://gathercontent.com/blog/content-operations-model-of-maturity.

18 "Understanding the Content Maturity Model," Content Strategy Inc. (blog), March 2016, https://www.contentstrategyinc.com/understanding-content-maturity-model/.

${ }^{19}$ Jones, “A Content Operations Maturity Model," sec. A maturity model for content operations.

20 Zoë Randolph, “Where Do You Fall on the Content Operations Maturity Model?,” sec. The Content Operations Maturity Model, Kapost Blog (blog), April 20, 2020, https://kapost.com/b/content-operations-maturity-model/.

21 Tracy Playle, "Ten Pillars for Getting the Most of Your Content: How Is Your University Doing?," Pickle Jar Communications (blog), September 29, 2017, http://www.picklejarcommunications.com/2017/09/29/content-strategy-benchmarking/.

22 “Email Marketing Benchmarks by Industry," Mailchimp, accessed June 15, 2020, https://mailchimp.com/resources/email-marketing-benchmarks/.

${ }^{23}$ Some libraries are members of multiple groups. 


\section{APPENDICES}

Appendix A: Institution List

Appendix B: Recruitment Emails

Appendix C: Survey Questions

Appendix D: Informed Consent Document

Appendix E: Other Content Management Systems Mentioned by Respondents

Appendix F: Organizational Responsibility for Content; and Position Titles

Appendix G: Definitions of Web Content Strategy 


\section{APPENDIX A: INSTITUTION LIST}

\begin{tabular}{|c|c|}
\hline Institution & Membership(s) \\
\hline Agnes Scott College & Oberlin Group \\
\hline Alabama & ARL \\
\hline Alberta & ARL \\
\hline Albion College & Oberlin Group \\
\hline Alma College & Oberlin Group \\
\hline Amherst College & Oberlin Group \\
\hline Arizona & ARL, GWLA \\
\hline Arizona State & ARL, GWLA \\
\hline Arkansas & GWLA \\
\hline Auburn & ARL \\
\hline Augustana College & Oberlin Group \\
\hline Austin College & Oberlin Group \\
\hline Bard College & Oberlin Group \\
\hline Barnard College & Oberlin Group \\
\hline Bates College & Oberlin Group \\
\hline Baylor & GWLA \\
\hline Beloit College & Oberlin Group \\
\hline Berea College & Oberlin Group \\
\hline Boston & ARL \\
\hline Boston College & ARL \\
\hline Boston Public Library & ARL \\
\hline Bowdoin College & Oberlin Group \\
\hline Brigham Young & ARL, GWLA \\
\hline British Columbia & ARL \\
\hline Brown & ARL \\
\hline Bryn Mawr College & Oberlin Group \\
\hline Bucknell University & Oberlin Group \\
\hline Calgary & ARL \\
\hline California, Berkeley & ARL \\
\hline California, Davis & ARL \\
\hline California, Irvine & ARL \\
\hline California, Los Angeles & ARL \\
\hline
\end{tabular}




\begin{tabular}{|l|l|}
\hline Institution & Membership(s) \\
\hline California, Riverside & ARL \\
\hline California, San Diego & ARL \\
\hline California, Santa Barbara & ARL \\
\hline Carleton College & Oberlin Group \\
\hline Case Western Reserve & ARL \\
\hline Chicago & ARL, BTAA \\
\hline Cincinnati & ARL \\
\hline Claremont Colleges & GWLA, Oberlin Group \\
\hline Clark University & Oberlin Group \\
\hline Coe College & Oberlin Group \\
\hline Colby College & Oberlin Group \\
\hline Colgate University & Oberlin Group \\
\hline College of the Holy Cross & Oberlin Group \\
\hline College of Wooster & Oberlin Group \\
\hline Colorado & ARL, GWLA \\
\hline Colorado College & Oberlin Group \\
\hline Colorado State & ARL, GWLA \\
\hline Columbia & ARL \\
\hline Connecticut & ARL \\
\hline Connecticut College & Oberlin Group \\
\hline Cornell & ARL \\
\hline Dartmouth & ARL \\
\hline Davidson College & Oberlin Group \\
\hline Delaware & ARL, GWLA \\
\hline Denison University & Oberlin Group \\
\hline Denver & GWLA \\
\hline DePauw University & Oberlin Group \\
\hline Dickinson College & Oberlin Group \\
\hline Drew University & Oberlin Group \\
\hline Duke & ARL \\
\hline Earlham College & Oberlin Group \\
\hline Eckerd College & Oberlin Group \\
\hline Emory & ARL \\
\hline & arios \\
\hline
\end{tabular}




\begin{tabular}{|l|l|}
\hline Institution & Membership(s) \\
\hline Florida & ARL \\
\hline Florida State & ARL \\
\hline Franklin \& Marshall College & Oberlin Group \\
\hline Furman University & Oberlin Group \\
\hline George Washington & ARL \\
\hline Georgetown & ARL \\
\hline Georgia & ARL \\
\hline Georgia Tech & ARL \\
\hline Gettysburg College & Oberlin Group \\
\hline Grinnell College & Oberlin Group \\
\hline Guelph & ARL \\
\hline Gustavus Adolphus College & Oberlin Group \\
\hline Hamilton College & Oberlin Group \\
\hline Harvard & ARL \\
\hline Haverford College & Oberlin Group \\
\hline Hawaii & ARL \\
\hline Hope College & Oberlin Group \\
\hline Houston & ARL, GWLA \\
\hline Howard & ARL \\
\hline Illinois, Chicago & ARL, GWLA \\
\hline Illinois, Urbana & ARL, BTAA \\
\hline Indiana & ARL, BTAA \\
\hline Iowa & ARL, BTAA \\
\hline Iowa State & ARL, GWLA \\
\hline Johns Hopkins & ARL \\
\hline Kalamazoo College & Oberlin Group \\
\hline Kansas & ARL, GWLA \\
\hline Kansas State & GWLA \\
\hline Kent State & ARL \\
\hline Kentucky & ARL \\
\hline Kenyon College & Oberlin Group \\
\hline Knox College & Oberlin Group \\
\hline Lafayette College & Oberlin Group \\
\hline & (a) \\
\hline
\end{tabular}




\begin{tabular}{|l|l|}
\hline Institution & Membership(s) \\
\hline Lake Forest College & Oberlin Group \\
\hline Laval & ARL \\
\hline Lawrence University & Oberlin Group \\
\hline Library Of Congress & ARL \\
\hline Louisiana State & ARL \\
\hline Louisville & ARL \\
\hline Macalester College & Oberlin Group \\
\hline Manhattan College & Oberlin Group \\
\hline Manitoba & ARL \\
\hline Maryland & ARL, BTAA \\
\hline Massachusetts & ARL \\
\hline Mcgill & ARL \\
\hline Mcmaster & ARL \\
\hline Miami & ARL \\
\hline Michigan & ARL, BTAA \\
\hline Michigan State & ARL, BTAA \\
\hline Middlebury College & Oberlin Group \\
\hline Mills College & Oberlin Group \\
\hline Minnesota & ARL, BTAA \\
\hline Missouri & ARL, GWLA \\
\hline Mit & ARL \\
\hline Morehouse/Spelman Colleges (AUC) & Oberlin Group \\
\hline Mount Holyoke College & Oberlin Group \\
\hline Nebraska & ARL, BTAA \\
\hline Nevada Las Vegas & GWLA \\
\hline New Mexico & ARL, GWLA \\
\hline New York & ARL \\
\hline North Carolina & ARL \\
\hline North Carolina State & ARL \\
\hline Northwestern & ARL, BTAA \\
\hline Notre Dame & ARL \\
\hline Oberlin College & Oberlin Group \\
\hline Occidental College & Oberlin Group \\
\hline
\end{tabular}




\begin{tabular}{|l|l|}
\hline Institution & Membership(s) \\
\hline Ohio & ARL \\
\hline Ohio State & ARL, BTAA \\
\hline Ohio Wesleyan University & Oberlin Group \\
\hline Oklahoma & ARL, GWLA \\
\hline Oklahoma State & ARL, GWLA \\
\hline Oregon & ARL, GWLA \\
\hline Oregon State & GWLA \\
\hline Ottawa & ARL \\
\hline Pennsylvania & ARL \\
\hline Pennsylvania State & ARL, BTAA \\
\hline Pittsburgh & ARL \\
\hline Princeton & ARL \\
\hline Purdue & ARL, BTAA \\
\hline Queen's & ARL \\
\hline Randolph-Macon College & Oberlin Group \\
\hline Reed College & Oberlin Group \\
\hline Rhodes College & Oberlin Group \\
\hline Rice & ARL, GWLA \\
\hline Rochester & ARL \\
\hline Rollins College & Oberlin Group \\
\hline Rutgers & ARL, BTAA \\
\hline Sarah Lawrence College & Oberlin Group \\
\hline Saskatchewan & ARL \\
\hline Sewanee: The University of the South & Oberlin Group \\
\hline Simmons University & Oberlin Group \\
\hline Simon Fraser & ARL \\
\hline Skidmore College & Oberlin Group \\
\hline Smith College & Oberlin Group \\
\hline South Carolina & ARL \\
\hline Southern California & ARL, GWLA \\
\hline Southern Illinois & ARL, GWLA \\
\hline Southern Methodist & GWLA \\
\hline St. John's University / College of St. Benedict & Oberlin Group \\
\hline & SigARS \\
\hline
\end{tabular}




\begin{tabular}{|l|l|}
\hline Institution & Membership(s) \\
\hline St. Lawrence University & Oberlin Group \\
\hline St. Olaf College & Oberlin Group \\
\hline Suny-Albany & ARL \\
\hline Suny-Buffalo & ARL \\
\hline Suny-Stony Brook & ARL \\
\hline Swarthmore College & Oberlin Group \\
\hline Syracuse & ARL \\
\hline Temple & ARL \\
\hline Tennessee & ARL \\
\hline Texas & ARL, GWLA \\
\hline Texas A\&M & ARL, GWLA \\
\hline Texas State & GWLA \\
\hline Texas Tech & ARL, GWLA \\
\hline Toronto & ARL \\
\hline Trinity College & Oberlin Group \\
\hline Trinity University & Oberlin Group \\
\hline Tulane & ARL \\
\hline Union College & Oberlin Group \\
\hline Utah & ARL, GWLA \\
\hline Utah State & GWLA \\
\hline Vanderbilt & ARL \\
\hline Vassar College & Oberlin Group \\
\hline Virginia & ARL \\
\hline Virginia Commonwealth & ARL \\
\hline Virginia Tech & ARL \\
\hline Wabash College & Oberlin Group \\
\hline Washington & ARL, GWLA \\
\hline Washington and Lee University & Oberlin Group \\
\hline Washington State & ARL, GWLA \\
\hline Washington U.-St. Louis & ARL, GWLA \\
\hline Waterloo & ARL \\
\hline Wayne State & ARL, GWLA \\
\hline Wellesley College & Oberlin Group \\
\hline & Sirofis \\
\hline
\end{tabular}




\begin{tabular}{|l|l|}
\hline Institution & Membership(s) \\
\hline Wesleyan University & Oberlin Group \\
\hline West Virginia & GWLA \\
\hline Western & ARL \\
\hline Wheaton College & Oberlin Group \\
\hline Whitman College & Oberlin Group \\
\hline Whittier College & Oberlin Group \\
\hline Willamette University & Oberlin Group \\
\hline Williams College & Oberlin Group \\
\hline Wisconsin & ARL, BTAA \\
\hline Wyoming & GWLA \\
\hline Yale & ARL \\
\hline York & ARL \\
\hline
\end{tabular}




\section{APPENDIX B: RECRUITMENT EMAILS}

\section{Recruitment Email: Named Recipients}

This message is intended for *|MMERGE6|*

Dear *|FNAME $\left.\right|^{*}$,

We are writing today to ask for your participation in a research project "Content Strategy in Practice within Academic Libraries," (CU Boulder IRB Protocol \#18-0670), led by co-investigators Courtney McDonald and Heidi Burkhardt (University of Michigan).

We have provided the information below as a $<$ link $>$ downloadable PDF $<$ link $>$ should you wish to keep it for your records.

The purpose of the study is to establish an understanding of the degree of institutional engagement in web content strategy within academic and research libraries, and what trends may be detected in this area of professional practice.

Our primary subject population consists of academic and research libraries that are members of the following nationally and regionally significant membership organizations (excluding nonacademic member institutions): Association of Research Libraries, Big Ten Academic Alliance, Greater Western Library Alliance, and/or the Oberlin Group.

If you opt to participate, we expect that you will be in this research study for the duration of the time it takes to complete our web-based survey.

You will not be paid to be in this study. Whether or not you take part in this research is your choice. You can leave the research at any time and it will not be held against you.

We expect about 210 people, representing their institutions, in the entire study internationally.

This survey will be available over a four-week period in the spring of 2020, through Friday, May 1.

We specifically identified you as a potential participant based on your role within your

organization and are only sending this to one person at each institution. If you are not

the appropriate participant, please forward accordingly.

(0) Someone else at your institution should respond? Forward this invitation.

\section{Access the survey}

** Confidentiality

Information obtained about you for this study will be kept confidential to the extent allowed by law. Research information that identifies you may be shared with the University of Colorado Boulder Institutional Review Board (IRB) and others who are responsible for ensuring compliance with laws and regulations related to research, including people on behalf of the Office for Human 
Research Protections. The information from this research may be published for scientific purposes; however, your identity will not be given out.

** Questions

If you have questions, concerns, or complaints, or think the research has hurt you, contact the research team at crmcdonald@colorado.edu.

This research has been reviewed and approved by an IRB. You may talk to them at (303) 7353702 or irbadmin@colorado.edu if:

* Your questions, concerns, or complaints are not being answered by the research team.

* You cannot reach the research team.

* You want to talk to someone besides the research team.

* You have questions about your rights as a research subject.

* You want to get information or provide input about this research.

Thank you for your consideration,

Courtney McDonald

crmcdonald@colorado.edu

Heidi Burkhardt

heidisb@umich.edu

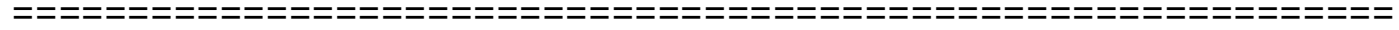

Not interested in participating?

You can ${ }^{* *}$ unsubscribe from this list $\left({ }^{*}|\mathrm{UNSUB}|^{*}\right)$.

This email was sent to *|EMAIL|* (mailto:*|EMAIL|*)

why did I get this? $\left({ }^{*} \mid\right.$ ABOUT_LIST $\left.\left.\right|^{*}\right) \quad$ unsubscribe from this list $\left({ }^{*} \mid\right.$ UNSUB $\left.\right|^{*}$ ) update subscription preferences (*|UPDATE_PROFILE ${ }^{*}$ ) 


\section{Recruitment Email: Named Recipients}

Dear library colleague,

We are writing today to ask for your participation in a research project "Content Strategy in Practice within Academic Libraries," (CU Boulder IRB Protocol \#18-0670), led by co-investigators Courtney McDonald and Heidi Burkhardt (University of Michigan).

Our primary subject population consists of academic and research libraries that are members of the following nationally and regionally significant membership organizations (excluding nonacademic member institutions): Association of Research Libraries, Big Ten Academic Alliance, Greater Western Library Alliance, and/or the Oberlin Group.

We ask that you forward this message to the person in your organization whose role includes oversight of your public web site. We are only requesting a response from one person at each institution contacted. Thank you for your assistance in routing this request.

(1) Forward this invitation to the appropriate person at your organization.

We have provided the information below as a $<$ link $>$ downloadable $\mathrm{PDF}<$ link $>$ should you wish to keep it for your records.

The purpose of the study is to establish an understanding of the degree of institutional engagement in web content strategy within academic and research libraries, and what trends may be detected in this area of professional practice.

If someone within your library opts to participate, we expect that person will be in this research study for the duration of the time it takes to complete our web-based survey.

The participant will not be paid to be in this study. Whether or not someone in your library takes part in this research is an individual choice. The participant can leave the research at any time and it will not be held against them.

We expect about 210 people, representing their institutions, in the entire study internationally.

This survey will be available over a four-week period in the spring of 2020, through Friday, May 1.

\section{Access the survey}

** Confidentiality

Information obtained about you for this study will be kept confidential to the extent allowed by law. Research information that identifies you may be shared with the University of Colorado Boulder Institutional Review Board (IRB) and others who are responsible for ensuring compliance with laws and regulations related to research, including people on behalf of the Office for Human Research Protections. The information from this research may be published for scientific purposes; however, your identity will not be given out. 
** Questions

If you have questions, concerns, or complaints, or think the research has hurt you, contact the research team at crmcdonald@colorado.edu.

This research has been reviewed and approved by an IRB. You may talk to them at (303) 735 3702 or irbadmin@colorado.edu if:

* Your questions, concerns, or complaints are not being answered by the research team.

* You cannot reach the research team.

* You want to talk to someone besides the research team.

* You have questions about your rights as a research subject.

* You want to get information or provide input about this research.

Thank you for your consideration,

Courtney McDonald

crmcdonald@colorado.edu

Heidi Burkhardt

heidisb@umich.edu

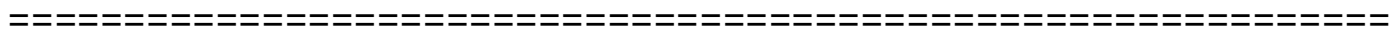

Not interested in participating?

You can ${ }^{* *}$ unsubscribe from this list $\left({ }^{*}|\mathrm{UNSUB}|^{*}\right)$.

This email was sent to *|EMAIL|* (mailto:*|EMAIL $\left.\right|^{*}$ )

why did I get this? $\left({ }^{*} \mid\right.$ ABOUT_LIST $\left.\mid *\right) \quad$ unsubscribe from this list $\left({ }^{*}|\mathrm{UNSUB}|^{*}\right) \quad$ update subscription preferences (*|UPDATE_PROFILE $\left.\right|^{*}$ ) 


\section{APPENDIX C: SURVEY QUESTIONS}

Web Content Strategy Methods and Maturity

\section{Start of Block: introduction}

Q1 Web Content Strategy Methods and Maturity in Academic Libraries (CU Boulder IRB Protocol \#20-0581)

Purpose of the Study The purpose of the study is to gather feedback from practitioners on the proposed Content Strategy Maturity Model for Academic Libraries, and to further enhance our understanding of web content strategy practice in academic libraries and the needs of its community of practice.

Q2 Please make a selection below, in lieu of your signature, to document that you have $<$ link $>$ read and understand the consent form $</$ link $>$, and voluntarily agree to take part in this research.

Yes, I consent to take part in this research. (1)

No, I do not grant my consent to take part in this research. (2) 
Q3 Estimated total number of employees (FTE) at your library organization:

Less than five (12)

$5-10(13)$

$11-20(14)$

21-99 (15)

100-199 (16)

$200+(17)$

Q4 Estimated number of employees with editing privileges within your primary library website:

Less than five (12)

$5-10(13)$

$11-20(14)$

21-99 (15)

100-199 (16)

$200+(17)$

Q5 Does your library have a documented web content strategy and / or a web content governance policy?

No (1)

Yes (2) 
Q6 Are there position(s) within your library whose primary duties are focused on creation, management, and/or editing of web content?

No (1)

Yes, including myself (2)

Yes, not including myself (3)

\section{End of Block: Demographic Information}

\section{Start of Block: Web Content Strategy}

Q7 Please indicate the degree to which each of the five elements of content strategy are currently in practice at your library.

Q8

\section{Creation}

Employ editorial workflows, consider content structure, support writing.

Definitely true Somewhat true Somewhat false

(48)

(49)

(50)

Definitely false

(51)

This is currently

in practice at my

institution. (1) 
Q9

Delivery

Consider findability, discoverability, and search engine optimization, plus choice of content platform or channels.

Definitely true Somewhat true Somewhat false Definitely false (48)

(49)

(50)

(51)

This is currently

in practice at my

institution. (1)

Q10

\section{Governance}

Support maintenance and lifecycle of content, as well as measurement and evaluation.

Definitely true Somewhat true Somewhat false Definitely false

(31)

(32)

(33)

(34)

This is currently

in practice at my

institution. (1)

\section{Q11}

\section{Planning}

Use an intentional and strategic approach, including brand, style, and writing best practices.

Definitely true

(31)
Somewhat true

(32)
Somewhat false

(33)
Definitely false (34)

This is currently

in practice at my institution. (1) 
Q12

User Experience

Consider needs of the user to produce relevant, current, clear, concise, and in context.

Definitely true Somewhat true Somewhat false Definitely false

(32)

(33)

(34)

This is currently

in practice at my

institution. (1)

Q13 Please rank the elements of content strategy (as defined above) in order of their priority based on your observations of practice in your library.

- ___ Creation (1)

- ___ Delivery (2)

- ___ Governance (3)

- ___ Planning (4)

- ___ User Experience (5)

Q14 How would you assess the content strategy maturity of your organization?

Basic (1)

Intermediate (2)

Advanced (3) 


\section{Start of Block: Thank you!}

Q15 Your name:

Q16 Thank you very much for your willingness to be interviewed as part of our research study. Prior to continuing on to finalize your survey submission, please sign up for an interview time:

[link]

(this link will open in a new window in order to allow you to finalize and submit your survey response after scheduling an appointment)

Please contact Courtney McDonald, crmcdonald@colorado.edu, if you experience any difficulty in registering or if there is not a time available that works for your schedule. 


\section{APPENDIX D: INFORMED CONSENT DOCUMENT}

Permission to Take Part in a Human Research Study

28

Title of research study: Content Strategy in Practice within Academic Libraries

\section{IRB Protocol Number: 18-0670}

\section{Investigators: Courtney McDonald and Heidi Burkhardt}

Purpose of the Study

The purpose of the study is to establish an understanding of the degree of institutional engagement in web content strategy within academic and research libraries, and what trends may be detected in this area of professional practice.

Our primary subject population consists of academic and research libraries that are members of the following nationally and regionally significant membership organizations (excluding nonacademic member institutions): Association of Research Libraries, Big Ten Academic Alliance, and/or Greater Western Library Alliance.

We expect that you will be in this research study for the duration of the time it takes to complete our web-based survey.

We expect about 210 people, representing their institutions, in the entire study internationally.

\section{Explanation of Procedures}

We are directly contacting each library to request that the appropriate individual(s) complete a web-based survey. This survey will be available over a four-week period in the spring of 2020 .

\section{Voluntary Participation and Withdrawal}

Whether or not you take part in this research is your choice. You can leave the research at any time and it will not be held against you.

The person in charge of the research study can remove you from the research study without your approval. Possible reasons for removal include an incomplete survey submission.

\section{Confidentiality}

Information obtained about you for this study will be kept confidential to the extent allowed by law. Research information that identifies you may be shared with the University of Colorado Boulder Institutional Review Board (IRB) and others who are responsible for ensuring compliance with laws and regulations related to research, including people on behalf of the Office for Human Research Protections. The information from this research may be published for scientific purposes; however, your identity will not be given out.

\section{Payment for Participation}

You will not be paid to be in this study.

\section{Contact for Future Studies}

We would like to keep your contact information on file so we can notify you if we have future research studies we think you may be interested in. This information will be used by only the 
principal investigator of this study and only for this purpose. You can opt-in to provide your contact information at the end of the online survey.

\section{Questions}

If you have questions, concerns, or complaints, or think the research has hurt you, contact to the research team at crmcdonald@colorado.edu

This research has been reviewed and approved by an IRB. You may talk to them at (303) 7353702 or irbadmin@colorado.edu if:

- Your questions, concerns, or complaints are not being answered by the research team.

- You cannot reach the research team.

- You want to talk to someone besides the research team.

- You have questions about your rights as a research subject.

- You want to get information or provide input about this research.

\section{Signatures}

In lieu of your signature, your acknowledgement of this statement in the online survey document documents your permission to take part in this research. 


\section{APPENDIX E: OTHER CONTENT MANAGEMENT SYSTEMS MENTIONED BY RESPONDENTS}

Question \#4: Which of the following content management systems does your library use to manage library-authored web content?

Write-in responses for 'Proprietary system hosted by institution'

- ArchivesSpace

- Pressbooks

- Preservica

- Hippo CMS

- Siteleaf

- Cascade

- $\operatorname{dotCMS}$

- Terminal Four

- Acquia Drupal

- Fedora based digital collections system built in house

Write-in responses for 'Other"

- wiki and blog

- We draft content in Google Docs \& also use Gather Content for auditing.

- Google Sites

- Cascade

- Ebsco Stacks

- MODX

- Islandora and Online Journal System

- Contentful

- We also have some in-house-built tools such as for room booking; some of these are quite old and we would like to upgrade or improve them when we can. (Very few people can make edits in these tools.)

- Cascade

- The majority of the library website (and University website) is managed by a locally developed CMS; however, the University is in the process of migrating to the Acquia Drupal CMS.

- Blacklight, Vivo, Fedora

- Most pages are just Non-CMS for the website 


\section{APPENDIX F: ORGANIZATIONAL RESPONSIBILITY FOR CONTENT; AND POSITION TITLES}

\section{Question 6}

Please explain how your organization distributes responsibility for content hosted in your content management system(s). If different parties (individuals, departments, collaborative groups) are responsible for managing content in different platforms please describe.

- We have one primary website manager who oversees the management of the website, including content strategy and editing, and 2 editors who assist with small editing tasks.

- We have content editors that edit content for individual libraries and collections. There is a content creator network managed by library communications. They provide trainings and guidance for content editors and act as reviewers, but not every single thing gets reviewed.

- We have a team of developers and product owners who are responsible for managing web content.

- We currently have a very distributed model, where virtually any library staff member or student assistant can request a Drupal account and then make changes to existing content or develop new pages. We have a cross-departmental team that oversees the Libraries' web interfaces and makes decisions about library homepage content, the menu navigation, overall IA, etc. We have web content guidelines to help staff as they develop new content. We have identified functional and technical owners for each of our CMSs and have slightly different processes for managing content in those CMSs. Our general approach, however, is very inclusive (for better or worse ;) )-- lots of staff have access to creating and editing content.

We are, however, moving to a less distributed content for Drupal in particular. Moving forward, we'll have a small team responsible for editing and developing new content. This is to ensure that content is more consistent and user-centered. We attempted to identify funding for a full-time content manager but were unsuccessful, so this team will attempt to fill the role of a full-time content manager.

- UX is the product owner and admin. If staff want content added to the website, they send a request to UX, we structure and edit content in a google doc, and then UX posts to the website.

- There's no method for how or why responsibility is distributed. It ends up being something like, someone wants to add some content, they get editing access, they can now edit anything for as long as they're at the library. We are a super decentralized and informal library.

- The primary content managers are the $\quad$ Librarian and the $\quad$ Other individuals (primarily librarians) that are interested in editing their content have access on our development server. Their edits are vetted by the _ and/or the _ Librarian before being moved into production.

- The department (6 staff) manages content and helps staff throughout the organization create and maintain content. UX staff sometimes teach others how to manage content, and sometimes do it for them. If design or content is complex, usually UX staff do the work. Many staff don't maintain any content beyond their staff pages. Subject specialists and instruction librarians maintain content [like] LibGuides-like content, but we don't use LibGuides. Branch library staff maintain most of the content for their library pages. 
- In addition, the manages the catalog. The department manages special web projects. And the department manages social media, publications, and news.

- A Web Content Team made up of two administrators and librarians from $\square$ and makes executive-level decisions about web content.

- The Team ( $\quad$ provides oversight and consulting for online user interfaces chaired by a position which is new and is not yet filled.

- For the public website, content editing is distributed to many groups and teams throughout the libraries.

- The team manages the main portions of the site including the homepage, news, maps, calendars, etc. The research librarians and subject liaisons manage the research guides. The provides guidance regarding overall responsibilities and style guidelines.

- Site structure and top-level pages for our main website resides with $\quad$. Page content is generally distributed to the departments closest to the services described by the pages.

- Right now editing of pages is distributed to those individuals who have the closest relationship to the pages being edited, with a significantly smaller number of people having administrative access to all of the libraries' websites.

- Primary website is co-managed by team (4 people) and t team (3 people). team creates timely content about news/events/initiatives while _ team manages content on evergreen topics.

- Research librarians and staff manage LibGuides content, which is in sore need of an inventory and pruning.

- Primarily me, plus two colleagues who serve with me as a web editorial board

- One librarian manages the content and makes changes based on requests from other library staff

- My role ( We also have a web content creator in our Is . I chair our Group (_), which has representatives from each division in the library and they are the primary stewards of supporting library authored web content. Our "speciality" platforms (LibGuides, Omeka, and WordPress for microsites) all have service leads, but content is managed by the respective stakeholders. The lead for LibGuides is a [group] member due to its scope and scale. In our primary website, we are currently structured around Drupal Organic Groups for content management with [group] having broad editing access. In our new website, all content management will go through the with Communications for support and dynamic content (homepage, news, events) management.

- Management is somewhat in flux right now. We recently migrated our main web site to Acquia Drupal; there is a very new small committee consisting of $\_$, and three representatives from elsewhere in the library. For LibGuides, all reference, instruction, and subject librarians can edit their own guides; the has tended to have final oversight but I don't know if this has ever been formally delegated.

- Librarians manage their own LibGuides subject guides; Several members of make administrative changes to coding, certificates, etc. on the entire site; there are individuals in different departments who control their own pages/LibGuides. There is a group within the library that administers Wordpress for the institution. Other content systems are administered by individuals within the library. 
- Librarians are responsible for their own LibGuides. The department manages changes to most content, although some staff do manage their own WordPress content. They tend not to want to.

- Individuals. Mainly one person authors content. The other individual has created some research guides.

- Individuals in different positions and departments within the library are assigned roles based on the type of content they frequently need to edit.

- For instance, staff have the ability to create and edit Exhibition content in Drupal. staff and staff have the ability to create and edit equipment content. The event coordinator and librarians and staff involved in instruction are allowed to create and edit event and workshop listings.

- Only the communication coordinator is permitted to create news items that occupy real estate on the home page and various service point home pages.

- As for general content, the primary internal stakeholders for that content typically create and edit that content, but if any staff notice a typo or factual error they are encouraged to correct them on their own, although they can also submit a request to the IT department if they are not comfortable doing so.

- Subject specific content is hosted in LibGuides, and is maintained by subject liaison librarians. Other content in LibGuides, software tutorials or information related to electronic resources for example, is created and maintained by appropriate specialists.

- The Drupal site when launched had internal stakeholders explicitly defined for each page, and only staff from the appropriate group could edit that content (e.g. if $\quad$ was tagged as the only stakeholder for a page about policies, then only staff from the department with editing privileges could edit that page). This system was abandoned after about two years as it was considered too much overhead to maintain and also the introduction of a content revisioning module that kept a history of edits alleviated fears of malicious editing.

- Individuals are assigned pages to keep content updated. The $\quad$ is responsible for coordinating with those staff and offers training to make sure content gets updated.

- Individual liaison librarians are responsible for their own LibGuides. I and the " are the primary editors of the WordPress site, although 4 others have editing access (an employee who writes and posts News articles, the liaison librarian who spearheaded our new video tutorials, and two who work in Special Collections to update finding aids on that site, which is still on WordPress and I would consider under the main libraries web page, but is part of a multisite installation.)

- In Omeka and LibGuides, librarians are pretty self-sufficient and responsible for all of their own content. The three or four digital projects faculty and staff who work with Omeka manage it internally alongside one of our developers. Our Omeka instance is relatively small-scale.

- I ( oversee our LibGuides environment. While I am in the process of creating and implementing formal LibGuides content and structure guidelines, as of now it's a bit of a free-for-all with everyone responsible for the content pertaining to their own liaison department(s). Content is made available to patrons via automatically populating legacy landing pages (we've had LibGuides for a decade and I've been with the institution not yet a year). 
- As the I am ultimately responsible for almost all of the content in our WordPress environment. That said, I try to distribute content upkeep responsibilities to the relevant department for each piece of the site. Managers and committee chairs provide me with what they want on the web, and as needed (and in consultation with them) I review/rewrite it for the web (plain language), develop information architecture, design the front-end, and accessibly publish the content. There are only a few faculty and staff at my library who are comfortable with WordPress -- but one of my long-term goals is to empower more folks to enact their own minor edits (e.g., updating hours, lending policies, etc.) while I oversee large-scale content creation, overall architecture, and strategy. We have a blog portion of our WordPress site which is not managed by anyone in particular, but I tend to clean it up if things go awry.

- Generally all of our web authors *can* publish to most parts of the site. (A very few content types (mostly featured images that display on home pages) can be edited only by admins and a small number of super-users.) However the great majority of people who can post content very rarely do (and some never do). Some edit or post only to specific blogs, some only to their own guides or to very specific pages or suites of pages (e.g. liaison librarians to their own guides; thesis assistant to thesis pages). Our small group in reviews new and updated pages and edits for in-house style and usability guidelines, and also trains and works collaboratively with web authors to create more usable content and reduce duplication -- but given the large number of authors (with varied priorities, skills, and preferences) and pages we have trouble keeping up. We also more actively manage content on home pages.

- For the main website and intranet, we have areas broken apart by unit area. We use workbench access to determine who can edit which pages. Libguides is managed by committee, but most of the librarians have access. Proprietary systems have separate accounts for those who need access.

- For LibGuides, librarians can create content as they like, though there is a group that provides some (light) oversight. For main library website, most content is overseen by departments (in practice, one person each from a handful of "areas", such as the branches, access services, etc.).

- DotCMS is primarily managed in Systems (2 staff), with delegates from admin and outreach allowed to make limited changes to achieve their goals. LibGuides is used by all librarians and several staff, with six people given admin privileges. Wordpress is used only in Special Collections.

- Dept manages major public facing platforms (Drupal, WordPress, and shares Libguides responsibilities with Dept). manages Omeka. Within platforms, responsibilities are largely managed by department with individuals assigned content duties \& permissions as needed.

- Different units maintain their content; one unit has overall management and checks for uniformity, needed updates, and broken links.

- Developers/communications office oversees some aspects, library management, research and collections librarians, and key staff edit other pieces.

- Currently, content is maintained by the librarian in coordination with content stakeholders from around the organization. We are in the process of migrating our site from Drupal to OmniUpdate. Once that is complete, we will develop a new model for content responsibilities. 
- Content is provided by department/services.

- 5 librarians manage the Libguides

\section{Question 9}

Titles of positions in your organization whose primary duties involve creation, management and/or editing of web content:

- Head of Web Services; Developer; Web Designer; User Experience Librarian

- User Experience Librarian, Lead Librarian for Discovery Systems, Digital Technologies Development Librarian, Lead Librarian for Software Development. And we have titles that are university system IT titles that don't mean a whole lot, such as Technology Support Specialist and Business and Technology Applications Analyst.

- Web Content Specialist

- User Experience Strategist, User Experience Designer, User Experience Student Assistants, Director of Marketing Communications and Events

- Sr. UX Specialist

- Web Support Consultant; Coordinator, Web Services \& Library Technology

- $\quad$ Editor \& Content Strategist in library communications

- Web Manager

- Discovery \& Systems Librarian

- Head of Library Systems and Technology

- Web Services and Data Librarian

- Communications Manager

- Web Content and User Experience Specialist

- Metadata and Discovery Systems Librarian, Systems Analyst, Outreach Librarian

- Digital Services Librarian; Manager, Communication Services; Communication Specialist

- (1) Web Project Manager and Content Strategist, (2) Web Content Creator

- Web Services Librarian

- Web Developer II

- Sr. Software Engineer, Program Director for Digital Services

- User Experience Librarian

- Digital Initiatives \& Scholarly Communication Librarian; Senior Library Associate in Digital Scholarship and Services

- Web Services and Usability Librarian

- Senior Library Specialist -- Web Content

- Web Developer, software development librarian 


\section{APPENDIX G: DEFINITIONS OF WEB CONTENT STRATEGY}

\section{Question 11}

In your own words, please define web content strategy.

- A cohesive plan to create an overall strategy for web content that includes tone, terminology, structure, and deployment to best communicate the institution's message and enable the user. For the next question, the true answer is sort of. We have the start of a style guide. We also have the University's branding policies. We also have a web governance committee that is university-wide, of which I'm a part of. However, we don't have a complete strategy and it is certainly not documented. So you pick.

- Planning, development, and management of web content. Two particularly important parts of web content strategy for academic library websites: 1 . keeping content up to date and unpublishing outdated content. 2. Building consensus for the creation and maintenance of a Web Style Guide and ensuring that content across the large website adheres to the style guide.

- Strategies for management of content over its entire lifecycle to ensure it is accurate, timely, usable, accessible, appropriate, findable, and well-organized.

- A system of workflows, training, and governance that supports the entire lifecycle of content, including creation, maintenance, and updating of content across all communications channels (e.g. websites, social media, signage).

- A comprehensive, coordinated, planned approach to content across the site including components such as style guides, accessibility, information architecture, discoverability, SEO.

- Not terribly familiar with the concept in a formal sense but think of it related to how the institution considers the intersection of content made available by the institution, the management and governance of issues such as branding/identity, accessibility, design, marketing, etc.

- Intentional and coordinated vision for content on the website

- Content strategy is the planning for the lifecycle of content. It includes creating, editing, reviewing, and deleting content. We also use a content strategy framework to determine each of the following for the content on our websites: audience, page goal, value proposition, validation, and measurement strategy.

- Website targets the community to ensure they can find what they need

- The process of creating and enacting a vision for the organization and display of web content so that it is user friendly, accurate, up-to-date, and effective in its message. Web content strategy often involves considering the thoughts and needs of many stakeholders, and creating one cohesive voice to represent them all.

- Web content strategy is the planning, design, delivery and governance plan for a website. This responsibility is guided by the library website management working group.

- A web content strategy is a cohesive approach to managing and editing online content. An effective strategy takes into account web accessibility standards and endeavors to produce and maintain consistent, reliable, user-centered content. An effective content strategy evolves to meet the needs of online users and involves regular user testing and reviews of web traffic/analytics.

- Web content strategy is the theory and practice of creating, managing, and publishing web content according to evidence-based best practices for usability and readability 
- Making sure your content aligns with both your business goals and your audience needs.

- A plan to oversee the life cycle of useful, usable content from its creation through maintenance and ultimately removal.

- Web content strategy is the overarching strategy for how you develop and disseminate web content. Ideally, it would be structured and user tested to ensure that the content you are spending time developing is meeting the needs of your library and your com munity.

- A web content strategy guides the full lifecycle of web content, including creation, maintenance, assessment, and retirement. It also sets guiding principles, makes responsibility and authority clear, and documents workflows.

- An overarching method of bringing user experience best practices together on the website including: heuristics, information architecture, and writing for the web

- Planning and management of online content

- A defined strategy for creating and delivering effective content to a defined audience at the right time.

- In the most basic sense, web content strategy is matching the content, services and functionality of web properties with the organizational strategic goals.

- Web content strategy can include guidelines, processes, and/or approaches to making your website(s) usable, sustainable, and findable. It's a big-picture or higher-level way of thinking about your site(s), rather than page by page or function by function.

- Deliberate structures and practices to plan, deliver, and evaluate web content.

- producing content that will be useful to users and easy for them to access

- Tying content to user behavior/user experience?

- Web content strategy is the thoughtful planning and construction of website content to meet users' needs.

- $\mathrm{n} / \mathrm{a}$

- Cohesive planning, development, and management of web content, to engage and support library users.

- Working with teams and thinking strategically and holistically about the usability, functions, services, information, etc. provided on the website to best meet the needs of the site's users, as well as incorporating the marketing/promotional perspectives offered by the website.

- planning and managing web content

- Web content strategy is the idea that all written and visual information on a certain site would conform to or align with the goals for that site.

- Ensuring that the most accurate and appropriate words, images, and other assets are presented to patrons at the point of need, while using web assets to tell stories patrons might not know they want to know. 